\title{
Peningkatan Hasil Belajar Matematika dengan Media Google Classroom dan WhatsApp Sebagai Media Pembelajaran Daring pada Masa Pandemi Covid-19 bagi Siswa Kelas XII Busana 2 SMK Negeri 3 Baubau
}

\author{
Amlin \\ SMK Negeri 3 Baubau, Kota Baubau - Provinsi Sulawesi Tenggara \\ Corresponding Author. Email: amlin.afifah@gmail.com
}

\begin{abstract}
This study aims to describe the improvement of student learning outcomes in mathematics subjects in statistics through Google Classroom and WhatsApp media. This research is a classroom action research in which the teacher plays a direct role in the online learning process. The subjects in this study were 32 students of class XII Busana 2 SMK Negeri 3 Baubau and the object of this research was to increase student learning outcomes with Google Classroom and WhatsApp media. The research instrument uses a test (daily test) in the form of an essay. The test is used to find out the results of learning mathematics. Based on the data analysis of students' mathematics learning outcomes in cycle I, there were 23 students who completed $(71.88 \%$ ) and those who had not completed $9(28.12 \%)$, while in cycle II who completed it became 27 students $(84.38 \%)$ and unfinished 5 students $(15.62 \%)$ with an increase in the average value of the cycle I is 73.13 while the average value of the cycle II is 81.56 which has increased significantly, so based on the results of the data analysis obtained it can be concluded that with Google Classroom and WhatsApp media can improve student learning outcomes for class XII Busana 2 SMK Negeri 3 Baubau.
\end{abstract}

Abstrak: Penelitian ini bertujuan untuk mendeskripsikan peningkatan hasil belajar siswa pada mata pelajaran matematika materi statistika melalui media Google Classroom dan WhatsApp. Penelitian ini merupakan penelitian tindakan kelas yaitu guru berperan langsung dalam proses pembelajaran secara daring. Subyek dalam penelitian ini dilakukan pada siswa kelas XII Busana 2 SMK Negeri 3 Baubau sejumlah 32 siswa dan objek penelitian ini adalah peningkatan hasil belajar siswa dengan media Google Classroom dan WhatsApp . Instrumen penelitian ini menggunakan tes (ulangan harian) berbentuk essay. Tes digunakan untuk mengetahui hasil belajar matematika. Berdasarkan analisis data hasil belajar matematika siswa pada siklus I adalah 23 siswa yang tuntas $(71,88 \%)$ dan yang belum tuntas 9 siswa $(28,12 \%)$, sedangkan pada siklus II yang tuntas menjadi 27 siswa $(84,38 \%)$ dan yang belum tuntas 5 siswa $(15,62$ $\%$ ) dengan peningkatan nilai rata-rata siklus I adalah 73,13 sedangkan nilai ratarata siklus II adalah 81,56 yang mengalami peningkatan secara signifikan, sehingga berdasarkan hasil analisis data yang diperoleh dapat disimpulkan bahwa dengan media Google Classroom dan WhatsApp dapat meningkatkan hasil belajar siswa kelas XII Busana 2 SMK Negeri 3 Baubau.

\section{Article History \\ Received: 25-05-2021 \\ Revised: 12-06-2021 \\ Accepted: 25-06-2021 \\ Published: 07-07-2021}

\section{Key Words:}

Learning Outcomes, Mathematics, Google Classroom, Whatsapp, Media.

\section{Sejarah Artikel \\ Diterima: 25-05-2021 \\ Direvisi: 12-06-2021 \\ Disetujui: 25-06-2021 \\ Diterbitkan: 07-07-2021}

\section{Kata Kunci: \\ Hasil Belajar, \\ Matematika, Media,. \\ Google Classroom, \\ Whatsapp .}

How to Cite: Amlin, A. (2021). Peningkatan Hasil Belajar Matematika dengan Media Google Classroom dan WhatsApp Sebagai Media Pembelajaran Daring pada Masa Pandemi Covid-19 bagi Siswa Kelas XII Busana 2 SMK Negeri 3 Baubau. Jurnal Paedagogy, 8(3), 431-437. doi:https://doi.org/10.33394/jp.v8i3.3907

https://doi.org/10.33394/jp.v8i3.3907

This is an open-access article under the CC-BY-SA License.

\section{Pendahuluan}

Pada era revolusi industri 4.0 adalah era dimana perkembangan zaman menuntut perubahan sikap dan cara berpikir kita. Dengan adanya kemajuan teknologi, maka manusia yang hidup di era sekarang harus mampu untuk memanfaatkan teknologi secara baik dan 
benar. Banyak hal baru yang muncul akibat perubahan zaman, salah satunya adalah pembelajaran. Dalam hal ini, media yang digunakan tidak hanya secara luring namun juga secara daring. Sejalan sejak diberlakukannya masa darurat Covid-19 pada tanggal 16 Maret 2020 dan sampai saat ini, hampir seluruh sekolah di Indonesia mengambil kebijakan untuk pembelajaran via daring atau disebut dengan pembelajaran jarak jauh (PJJ). Dengan adanya pembelajaran daring guru dan siswa sama-sama belajar untuk memanfaatkan teknologi sebagai media pembelajaran.

Dalam melaksanakan pembelajaran daring dengan berbagai keterbatasan kemampuan, sarana dan prasarana berupa handphone, laptop dan jaringan bagi guru dan siswa serta kemampuan yang masih terbatas dalam pemanfaatan teknologi membuat pelaksanaan pembelajaran daring harus tetap diupayakan berjalan agar proses transformasi ilmu pengetahuan kepada siswa tidak terganggu.

Guru sebagai ujung tombak pendidikan di masa pandemi Covid-19 wajib menerapkan pembelajaran jarak jauh (PJJ) melalui media Group Whatsapp, Google Classroom, Moodle, dan aplikasi belajar online lainnya (Nuryaningsih, 2021; Liubana \& Puspasari, 2021; Yulfianti \& Dewi, 2021). Untuk pembelajaran secara sinkronus guru juga memanfaatkan media Google Meet, Zoom Cloud Meeting, Cisco Webex dan lain sebagainya. Saat ini banyak sekali sumber belajar online serta konten ilmu yang terdapat di internet. Pemanfaatan berbagai media pembelajaran jarak jauh (PJJ) yang diolah sesuai dengan kemampuan dan keinginan guru. Tuntutan guru tidak hanya secara akademis tetapi juga kemampuan untuk berkomunikasi yang harus dilakukan dalam pembelajaran jarak jauh (PJJ) Seperti pada media pembelajaran Google Classroom, Moodle dan Group Whatsapp, guru mengirimkan materi pembelajaran, link video pembelajaran, tugas serta sebagai media komunikasi untuk melaksankan proses pembimbingan dan pendampingan kepada siswa.

Dengan berbagai keterbatasan dalam situasi pandemi Covid-19 menjadi tantangan seorang guru untuk terus mau belajar dan berlatih memanfaatkan media pembelajaran secara daring. Disamping itu guru harus mampu menghadirkan pembelajaran yang menyenangkan dan inovatif untuk mengatasi kesulitan belajar yang dihadapi serta kolaborasi media pembelajaran agar pembelajaran tidak monoton dan tetap bisa menghadirkan suasana pembelajaran interaktif antara guru dan siswa. Google Classroom adalah platform gratis berbasis web yang dibuat untuk mempermudah kegiatan pembelajaran pendidik dan siswa. Google Classroom adalah media yang di gunakan pada pembelajaran secara daring di sekolah kami di masa pandemik Covid-19. Para murid bisa menerima dan mengumpulkan tugas langsung di Google Classroom, begitu juga para guru. Layanan ini dapat sangat mengurangi penggunaan kertas dan mempermudah proses pembelajaran, apalagi jika dilakukan secara jarak jauh.

Google Classroom dirancang untuk mempermudah interaksi pendidik dan siswa dalam dunia maya. Pengalaman peneliti pada semester sebelumnya dalam pembelajaran daring menggunakan media Google Classroom, mayoritas siswa kurang dalam berinteraksi dan terkadang hanya mengisi daftar hadir pada saat pelajaran berlangsung. Penelitian ini mengkolaborasi dengan media WhatsApp, karena dalam diskusi di grup kelas interaktif siswa hampir semua aktif. Materi, latihan, tugas dikirim di Google Classroom dan diskusi dilakukan di WhatsApp grup. Pada level pendidikan tinggi WhatsApp hanya salah satu media. Berbeda dengan sekolah dasar, dari survei yang dilakukan peneliti 100\% belajar daring hanya 
menggunakan media WhatsApp grup (Rosarians et al., 2020; Harususilo, 2020). Salah satu solusi untuk meningkatkan hasil belajar siswa di masa pandemik Covid-19 dengan menggunakan media Google Classroom dan WhatsApp.

Nana Sudjana (2009) menjelaskan hasil belajar adalah kemampuan-kemampuan yang dimiliki siswa setelah menerima pengalaman belajar. Hasil belajar merupakan perilaku berupa pengetahuan, keterampilan, sikap, informasi, strategi kognitif yang baru dan diperoleh siswa setelah berinteraksi dengan lingkungan dalam suatu suasana atau kondisi pembelajaran. Selanjutnya Rosidha (2020) dan Susmiati (2020) menjelaskan bahwa hasil belajar yang baik dapat dicapai apabila siswa memahami apa yang telah mereka alami dalam proses belajar, dimana proses belajar yang menyenangkan akan memberikan pemahaman yang lebih pada siswa. Berdasarkan pengertian di atas dapat disimpulkan bahwa hasil belajar adalah ukuran tingkat keberhasilan yang dapat dicapai oleh seorang siswa berdasar pengalaman yang diperoleh setelah dilakukan evaluasi berupa tes dan biasanya diwujudkan dengan nilai tertentu serta menyebabkan terjadinya perubahan kognitif, afektif, maupun psikomotorik. Adapun tujuan penelitian ini adalah mendeskripsikan peningkatan hasil belajar matematika dengan media google classroom dan whatsapp sebagai media pembelajaran daring pada masa pandemi covid-19 bagi siswa kelas XII Busana 2 SMK Negeri 3 Baubau.

\section{Metode Penelitian}

Metode penelitian yang digunakan dalam penelitian ini adalah penelitian tindakan kelas atau Classroom Action Research (CAR). Menurut Suhardjono (2007). Penelitian tindakan kelas adalah penelitian tindakan yang dilakukan di kelas dengan tujuan memperbaiki atau meningkatkan mutu praktek pembelajaran. Prosedur penelitian tindakan kelas pada penelitian ini terdiri dari dua siklus, dimana pada siklus kegiatan pembelajaran dimulai dari perencanaan, pelaksanaan, obsevasi dan refleksi. Materi penelitian ini disesuaikan dengan peneliti ajarkan di kelas yaitu materi statistika. Subyek penelitian adalah siswa XII Busana 2 SMK Negeri 3 Baubau yang melibatkan 32 siswa. Penelitian dimulai tanggal 4 Januari sampai tanggal 2 Maret tahun 2021. Instrumen pengumpulan data adalah tes (ulangan harian). Tes (ulangan harian) digunakan untuk memperoleh data peningkatan hasil belajar. Teknik analisis data penelitian ini menggunakan analisis deskriptif kuantitatif dan kualitatif.

\section{Hasil Penelitian dan Pembahasan}

Penyajian hasil penelitian yang dianalisis adalah hasil belajar matematika siswa kelas XII Busana 2, setelah terjadi proses pembelajaran dengan menggunakan media Google Classroom dan WhatsApp skor nilai yang diperoleh siswa secara induvidu ataupun klasikal diharapkan memenuhi Kriteria Ketuntasan Minimal (KKM). Adapun Kriteria Ketuntasan Minimal (KKM) yang di tetapkan di SMK Negeri 3 Baubau untuk mata pelajaran matematika adalah 70 dan Ketuntasan secara Klasikal adalah minimal 75\% dari jumlah siswa.

Penelitian ini dilakasanakan 2 siklus yaitu siklus I dan siklus II masing masing siklus ada 2 kali pertemuan (1 kali pertemuan 4 jam pelajaran). Tahapan penelitian yang dilakukan pada siklus I adalah (1) tahap perencanaan yaitu menyiapkan kegiatan pembelajaran dengan membuat Rencana Pelaksanaan Pembelajaran (RPP), peneliti membuat akun Google Classroom melalui email berupa gmail dan membuat kode kelas XII Busana 2 SMK Negeri 3 Baubau. Peneliti juga membuat grup kelas di WhatsApp yaitu grup WhatsApp Matematika XII Busana 2 SMK Negeri 3 Baubau untuk dijadikan diskusi materi, latihan tugas dan kode 
kelas Google Classroom dikirim kepada siswa melalui grup WhatsApp Matematika XII Busana 2 SMK Negeri 3 Baubau, menyiapkan materi tes evaluasi, (2) tahap pelaksanaan yaitu siswa begabung di Google Classroom yang telah di berikan kode di WhatsApp, menyampaikan kepada siswa di grup WhatsApp untuk mengisi daftar hadir di menu kehadiran pada Google Classroom dan materi setiap pertemuan dengan cara membagikan materi di menu materi yang ada di Google Classroom dan siswa mengunduhnya setelah itu didiskusikan di menu forum. Kegiatan diskusi yang aktif di WhatsApp siswa menyapaikan permasalahan yang belum dimengerti. (3) tahap observasi mengamati diskusi siswa dengan melihat tanggapan materi yang diberikan, contoh soal, latihan dan mengunduh hasil pekerjaan siswa, (4) refleksi. Kegiatan refleksi pembelajaran dilakukan untuk mengetahui kelemahan pada siklus I. Beberapa materi yang dianggap sulit karena tidak adanya interaksi langsung (video conference) seperti menggunakan zoom atau googlemeets, sehingga siswa diperbolehkan bertanya melalui kolom komentar di Google Classroom atau melalui WhatsApp pribadi. Ada juga siswa hanya mengisi absen kehadiran di Google Classroom, materi dalam bentuk pdf yang di ada di menu materi pada Google Classroom tidak ditahu apakah sudah diunduh siswa atau belum. Peneliti mengupload materi dalam bentuk pdf di WhatsApp, karena di tahu siswa yang sudah baca materi tersebut. Kendala juga pada kuota internet yang menyebabkan tidak dapat mengikuti pelajaran, peneliti memberikan penjelasan kepada siswa agar kuota belajar yang dari kementerian pendidikan dan kuota paket dari sekolah digunakan hanya untuk proses pembelajaran daring tidak membuka fitur-fitur yang menyebabkan kuota belajar cepat habis. Tahap ini juga peneliti selalu memberikan motivasi kepada siswa untuk selalu aktif dalam proses pembelajaran.

\section{Tabel 1. Hasil Belajar Matematika Siklus I}

\begin{tabular}{cccc}
\hline No & Nama Siswa & Nilai UH 1 & Ketuntasan \\
\hline 1 & AN & 80 & Tuntas \\
2 & ANM & 70 & Tuntas \\
3 & AR & 80 & Tuntas \\
4 & CK & 65 & Tidak Tuntas \\
5 & D & 80 & Tuntas \\
6 & DTH & 70 & Tuntas \\
7 & E & 75 & Tuntas \\
8 & FS & 75 & Tuntas \\
9 & H & 60 & Tidak Tuntas \\
10 & INA & 75 & Tuntas \\
11 & J & 75 & Tuntas \\
12 & MDK & 75 & Tuntas \\
13 & M & 60 & Tidak Tuntas \\
14 & ML & 60 & Tidak Tuntas \\
15 & N & 85 & Tuntas \\
16 & NW & 65 & Tidak Tuntas \\
17 & NH & 90 & Tuntas \\
18 & NM & 70 & Tuntas \\
19 & NR & 65 & Tidak Tuntas \\
20 & NF & 80 & Tuntas \\
21 & NL & 80 & Tuntas \\
22 & NN & 75 & Tuntas \\
23 & PI & 85 & Tuntas
\end{tabular}




$\begin{array}{cccc}24 & \text { RFD } & 65 & \text { Tidak Tuntas } \\ 25 & \mathrm{R} & 80 & \text { Tuntas } \\ 26 & \text { S } & 80 & \text { Tuntas } \\ 27 & \text { SZ } & 60 & \text { Tidak Tuntas } \\ 28 & \text { WNA } & 80 & \text { Tuntas } \\ 29 & \text { WSY } & 80 & \text { Tuntas } \\ 30 & \text { WWZ } & 70 & \text { Tuntas } \\ 31 & \text { Y } & 55 & \text { Tidak Tuntas } \\ 32 & \text { YHS } & 75 & \text { Tuntas } \\ & \text { Jumlah nilai } & 2.340 & \\ & \text { Nilai rata-rata } & 73,13 & \end{array}$

Berdasarkan hasil tes (ulangan harian 1) siklus I dari 32 siswa ada $23(71,88 \%)$ siswa yang tuntas dan ada $9(28,12 \%)$ siswa yang tidak tuntas, hal ini dapat dilihat dari hasil unduhan siswa yang mengerjakan tes (ulangan harian 1) siklus I.

Tabel 2. Hasil Belajar Matematika Siklus II

\begin{tabular}{|c|c|c|c|}
\hline No & Nama Siswa & Nilai UH 2 & Ketuntasan \\
\hline 1 & $\mathrm{AN}$ & 95 & Tuntas \\
\hline 2 & ANM & 80 & Tuntas \\
\hline 3 & $\mathrm{AR}$ & 95 & Tuntas \\
\hline 4 & $\mathrm{CK}$ & 85 & Tuntas \\
\hline 5 & $\mathrm{D}$ & 90 & Tuntas \\
\hline 6 & DTH & 65 & Tidak Tuntas \\
\hline 7 & $\mathrm{E}$ & 75 & Tuntas \\
\hline 8 & FS & 90 & Tuntas \\
\hline 9 & $\mathrm{H}$ & 75 & Tuntas \\
\hline 10 & INA & 80 & Tuntas \\
\hline 11 & $\mathrm{~J}$ & 80 & Tuntas \\
\hline 12 & MDK & 80 & Tuntas \\
\hline 13 & M & 85 & Tuntas \\
\hline 14 & ML & 65 & Tidak Tuntas \\
\hline 15 & $\mathrm{~N}$ & 85 & Tuntas \\
\hline 16 & NW & 65 & Tidak Tuntas \\
\hline 17 & $\mathrm{NH}$ & 85 & Tuntas \\
\hline 18 & NM & 65 & Tidak Tuntas \\
\hline 19 & NR & 60 & Tidak Tuntas \\
\hline 20 & $\mathrm{NF}$ & 85 & Tuntas \\
\hline 21 & NL & 95 & Tuntas \\
\hline 22 & $\mathrm{NN}$ & 85 & Tuntas \\
\hline 23 & PI & 90 & Tuntas \\
\hline 24 & RFD & 80 & Tuntas \\
\hline 25 & $\mathrm{R}$ & 90 & Tuntas \\
\hline 26 & S & 85 & Tuntas \\
\hline 27 & $\mathrm{SZ}$ & 80 & Tuntas \\
\hline 28 & WNA & 85 & Tuntas \\
\hline 29 & WSY & 90 & Tuntas \\
\hline 30 & WWZ & 85 & Tuntas \\
\hline
\end{tabular}


31

32

\section{Y}

YHS
80

80

2.610

Jumlah nilai

81,56

Nilai rata-rata
Tuntas

Tuntas

Dalam pelaksanaan siklus II, guru melakukan langkah-langkah yang sama dengan langkah-langkah pada siklus I namun ada perbaikan pelaksanaan berdasarkan hasil refleksi pada siklus I. Berdasarkan hasil belajar pada siklus II dari 32 siswa ada 27 (84,38\%) siswa yang tuntas dan ada $5(15,62 \%)$ siswa yang tidak tuntas, hal ini dapat dilihat dari hasil unduhan siswa yang mengerjakan tes (ulangan harian 2) siklus II.

Tabel 3. Rekapitulasi Ketuntasan Belajar Siswa

\begin{tabular}{cccc}
\hline Siklus & $\begin{array}{c}\text { Persentase siswa yang } \\
\text { tuntas }\end{array}$ & $\begin{array}{c}\text { Persentase siswa } \\
\text { yang tidak tuntas }\end{array}$ & Nilai rata-rata \\
\hline Siklus I & 71,88 & 28,12 & 73,13 \\
Siklus II & 84,38 & 15,62 & 81,56 \\
\hline
\end{tabular}

Berdasarkan tabel 3 di atas maka dapat di gambarkan pada grafik berikut:

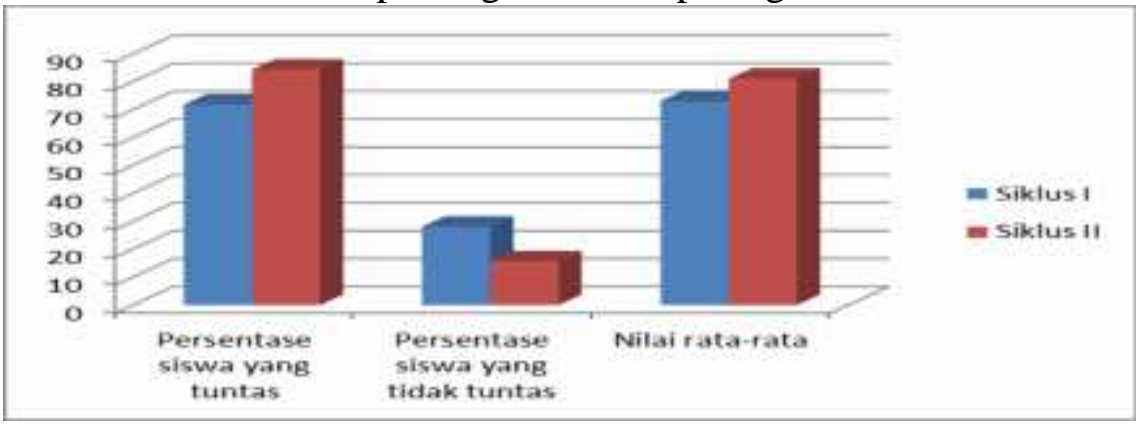

\section{Grafik 1. Rekapitulasi ketuntasan belajar siswa}

Pembelajaran dengan media Google Classroom dan WhatsApp dapat meningkatkan hasil belajar siswa pada masa pandemik Covid-19 pada mata pelajaran matematika karena dalam pelaksanaanya Google Classroom membuat mudah untuk guru dalam memberikan materi dan siswa juga mudah mengakses tugas atau materi dalam berbagai bentuk mulai dari dokumen, tulisan, foto, gambar, dan masih banyak lagi file yang dapat dikelola. Disamping itu juga Guru dapat mengirimkan materi pembelajaran berupa dokumen, foto, audio ataupun video kepada siswa melalui WhatsApp grup. Guru dan siswa dapat melihat dan mengulang materi pembelajaran melalui HP dengan mudah dan diskusi dapat berjalan aktif di WhatsApp sehingga setiap siswa dapat menguasai materi yang diberikan dan berdampak pada hasil belajar. Dalam melakukan pembelajaran daring ada beberapa kendala yang dialami siswa salah satunya adalah keterbatasan paket data, meskipun ada kuota belajar dari pemerintah dan bantuan sekolah dalam memenuhi kebutuhan kuota belajar siswa, dan paling utama adalah peran serta orang tua dalam mengontrol siswa dalam proses pembelajaran secara daring.

\section{Kesimpulan}

Berdasarkan hasil penelitian dan analisis data dipeoleh kesimpulan bahwa pembelajaran daring dengan media Google classroom dan WhatsApp pada masa pandemik Covid-19 dapat meningkatkan hasil belajar siswa mata pelajaran Matematika kelas XII Busana 2 di SMK Negeri 3 Baubau semester genap tahun pelajaran 2020/2021. Setelah pelaksanaan pembelajaran daring dengan media Google Classroom dan WhatsApp pada siklus I diperoleh 
nilai rata-rata 73,13, sedangkan siklus II diperoleh nilai rata-rata 81,56. Ketuntasan secara klasikal siklus I sebesar 71,88\% dan yang tidak tuntas sebesar $28,12 \%$ sedangkan ketuntasan siklus II sebesar $84,38 \%$ dan yang tidak tuntas $15,62 \%$.

\section{Saran}

Adapun saran yang disampaikan berdasarkan hasil penelitian ini adalah kepada guru matematika agar dapat mengkolaborasikan media Google Classroom dan WhatsApp dalam pembelajaran daring dimasa pandemik Covid-19 karena dapat meningkatkan hasil belajar siswa. Media Google Classroom dan WhatsApp membuat siswa termotivasi dalam belajar di masa pandemik Covid-19.

\section{Daftar Pustaka}

Ainur Rosidha. (2020). Peningkatan Aktifitas dan Hasil belajar Siswa pada Mata pelajaran Biologi Melalui Model Pembelajaran Make and Match Berbasis Media Kartu Belajar.Jurnal Paedagogy,7(4),145-149. doi: https://doi.org/10.33394/jp.v7i4.2946

Elis Nurhayati. (2020). Meningkatkan Keaktifan Siswa dalam Pembelajaran Daring melalui Media Game Edukasi Quiziz pada Masa Pencegahan penyebaran Covid-19. Jurnal Paedagogy, 7(3), 145-149. doi: https://doi.org/10.33394/jp.v7i3.2645

Liubana, A., \& Puspasari, D. (2021). Analisis Pengaruh Penggunaan E-Learning dengan Google Classroom dan Disiplin Belajar terhadap Motivasi Belajar Mahasiswa Brothers and Sisters House Kota Surabaya pada Masa Pandemi Covid-19. Jurnal Kependidikan: Jurnal Hasil Penelitian dan Kajian Kepustakaan di Bidang Pendidikan, Pengajaran dan Pembelajaran, 7(2), 417-427. doi:https://doi.org/10.33394/jk.v7i2.3599

Mirzon Daheri, dkk. (2020). Efektifitas WhatsApp sebagai Media Belajar Daring. Jurnal Basicedu, 4(4), 775-783. doi: https://doi.org/10.31004/basicedu.v4i4.445

Muhammad Arifin R, Bunyamin. (2020). Efektifitas Media Pembelajaran Daring melalui Google Classroom. Jurnal Pendidikan Islam, 11(2), 119-135. doi: https://doi.org/10.22236/jpi.v11i2.5974

Nana Sudjana. (2009). Penilaian Hasil Proses Belajar Mengajar. Bandung. Remaja Rosdakarya.

Nuryaningsih, W. (2021). Penerapan Model Discovery Learning Berkolaborasi Google Classroom dan WhatsApp Group untuk Meningkatkan Kompetensi Siswa dalam Menulis Teks Eksplanasi. Jurnal Paedagogy, $\quad 8(2), \quad$ 159-168. doi:https://doi.org/10.33394/jp.v8i2.3540

Suhardjono. (2007). Penelitian Tindakan Kelas. Jakarta. Bumi Aksara.

Yulfianti, S., \& Dewi, R. (2021). Efek Learning Management System Berbasis Google Classroom dan Minat Belajar Terhadap Hasil Belajar Ekonomi Siswa. Jurnal Kependidikan: Jurnal Hasil Penelitian dan Kajian Kepustakaan di Bidang Pendidikan, Pengajaran dan Pembelajaran, 7(2), 491-502. doi:https://doi.org/10.33394/jk.v7i2.3717 